\title{
Restricted Heterogeneity of T Lymphocytes in Combined Immunodeficiency with Hypereosinophilia (Omenn's Syndrome)
}

\author{
Geneviève de Saint-Basile, ${ }^{\star}$ Françoise Le Deist, ${ }^{\star}$ Jean-Pierre de Villartay, ${ }^{\star}$ Nadine Cerf-Bensussan, * \\ Odile Journet, ${ }^{*}$ Nicole Brousse, ${ }^{*}$ Claude Griscelli, ${ }^{*}$ and Alain Fischer ${ }^{*}$ \\ *Institut National de la Santé et de la Recherche Médicale, U 132, and ${ }^{\ddagger}$ Pathology Department \\ Hôpital Necker-Enfants Malades, 149, rue de Sèvres, 75743 Paris Cedex 15, France
}

\begin{abstract}
We report the immunological characteristics of five patients with Omenn's syndrome, a rare inherited immunodeficiency also known as combined immunodeficiency with hypereosinophilia. The syndrome is characterized by $T$ cell infiltration of skin, gut, liver, and spleen leading to diffuse erythroderma, protracted diarrhea, failure to thrive, and hepatosplenomegaly. Blood $T$ cells as well as those infiltrating the skin and gut were found to express activation markers and were partially activated by mitogens but not by antigens. Although the lesions resembled those in graft-versus-host disease, the blood $T$ cells were shown by DNA haplotype analysis using probes revealing variable number of tandem repeats to belong to the patients as well as the $\mathbf{T}$ cells infiltrating the gut and skin in one patient. $A$ given $\mathrm{T}$ cell subset $\left(\mathrm{TCR} \alpha \beta^{+}, \mathrm{CD4}^{+} / \mathrm{CD8}^{+}\right.$, or $\left.\mathrm{TCR} \gamma \delta^{+}\right)$was predominant in each patient, with a specific distribution in the skin lesions. Moreover, the study of T cell receptor $\beta, \gamma$, and $\delta$ gene rearrangements in four patients revealed oligoclonality involving $C \beta 1, C \beta 2$, or different $V \gamma \boldsymbol{J} \gamma$ or $V \delta J \delta$ genes. This indicates that restricted heterogeneity of the $T$ cell repertoire, previously reported in one case, is a major feature of this syndrome. The occurrence of alymphocytosis-type severe combined immunodeficiency in the brother of one of the patients suggests that the restricted heterogeneity of $T$ cell receptor gene usage in Omenn's syndrome may arise from leakiness, within the context of a genetically determined faulty $\mathbf{T}$ cell differentiation. (J. Clin. Invest. 87:1352-1359.) Key words: T cell activation $\cdot \mathbf{T}$ cell receptor $\bullet$ graft-versus-host reaction
\end{abstract}

\section{Introduction}

Omenn's syndrome or combined immunodeficiency with hypereosinophilia is characterized by the early occurrence of diffuse erythroderma, hepatosplenomegaly, protracted diarrhea, and failure to thrive (1-8). A large number of poorly functional $T$ cells and eosinophils are present in the blood and infiltrate the skin, gut, liver, and spleen (5-8). In contrast, the lymph nodes and thymus are profoundly depleted of lymphocytes. As the lesions are very similar to those observed in graft-versus-

Address reprint requests to Dr. Geneviève de Saint Basile, Institut National de la Santé et de la Recherche Médicale, U 132, Hôpital des Enfants Malades, 149 rue de Sèvres, 75743 Paris CEDEX 15, France. Received for publication 20 July 1990 and in revised form 26 November 1990

J. Clin. Invest.

(c) The American Society for Clinical Investigation, Inc. $0021-9738 / 91 / 04 / 1352 / 08 \quad \$ 2.00$

Volume 87, April 1991, 1352-1359 host disease (GVHD) ${ }^{1}(5-8)$ it has been proposed that GVHD is causal, but this has not been substantiated by the detection of foreign $T$ lymphocytes (5-9). The autosomal recessive inherited nature of the syndrome strongly suggests that it is a primary immunodeficiency (1). Wirt et al. have recently reported a large number of T cells of the CD4(-), CD8(-) $\alpha \beta \mathrm{T}$ cell receptor (TCR) subset in a patient with this syndrome. The $T$ cells were oligoclonal, as demonstrated by the presence of discrete bands of the $C \beta$ T cell receptor genes (9).

In this study we investigated the immunological characteristics of five patients with typical features of Omenn's syndrome. The $\mathrm{T}$ cells in each patient belonged to one predominant subset and displayed a restricted use of either $\alpha \beta$ or $\gamma \delta \mathrm{T}$ cell receptor genes, suggesting that $T$ cell oligoclonality is a hallmark of the syndrome.

\section{Methods}

Case reports. Five patients with a diagnosis of Omenn's syndrome were studied. Two were born of consanguineous parents (cases 1 and 2). Patients 1,3 , and 4 were single family cases, while a brother and a sister of patient 2 had died with the same syndrome and a brother of patient 5 had died with typical alymphocytosis-type severe combined immunodeficiency (SCID) (Fig. 1). The first manifestations appeared between 1 d and 2 mo of age and were characterized by diffuse erythroderma associated with pachyderma and alopecia of the scalp and eyebrows. Hepatosplenomegaly and lymph node enlargement were present in all but one case.

Repeated bacterial and fungal infections and severe diarrhea resulting in failure to thrive were a common feature. Patient 2 died at 1 mo of age of a lung infection and patient 5 died at $1 \mathrm{yr}$ from pneumonitis. The other three patients underwent bone marrow transplantation that was successful in two cases (3 and 4).

Biological investigations revealed hypereosinophilia and major immunological disorders. Serum IgG, IgM, and IgA levels were low while IgE levels were elevated in the four patients tested.

Cell isolation. Peripheral blood mononuclear cells (PBMC) were isolated from freshly drawn heparinized blood by means of Ficoll Hypaque (Pharmacia Fine Chemicals, Uppsala, Sweden) density centrifugation.

Surface marker analysis. The following MAbs were used: anti-CD1 (I0T6; Immunotech, Marseille, France); anti-CD3:Leu4 (Ig2a) (Becton Dickinson \& Co., Mountain View, CA); anti-T cell receptor $\beta$ :BMA031 (IgG1) (Behring Werke, Marburg, Germany); $\beta$ F1 (a gift from Dr. M. Brenner, Dana Farber Cancer Institute, Boston, MA); anti-T cell receptor $\delta:$ TCR $\delta 1$ (IgG1) (T Cell Sciences, Cambridge, MA); anti-V $\delta 1 \mathrm{~J} \delta 1: \delta \mathrm{TCS} 1$ (IgG1) (T cell Sciences); anti-V $\gamma 9$ (Ti $\gamma \mathrm{A}$ ); antiV $\delta 2$ (kindly provided by T. Hercend, IGR, Villejuif, France) (10); antiCD2:Leu5b (IgG2a) (Becton Dickinson); anti-CD4: Leu3a (IgG1)

1. Abbreviations used in this paper: GVHD, graft-versus-host disease; NK, natural killer; PCR, polymerase chain reaction; PE, phycoerythrin; SCID, severe combined immunodeficiency; TCR, T cell receptor; VNTR, variable number terminal repeats. 

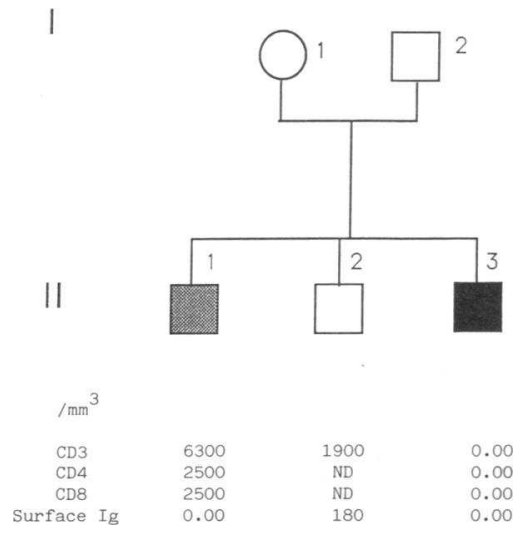

Figure 1. Pedigree of a child (II1) with Omenn's syndrome. Note the presence in the same family of a child with alymphocytosistype SCID (II3). The respective lymphocyte populations are reported for each sibling. $\square$ Male; o female. ND, not done.
(Becton Dickinson); anti-CD8:Leu2a (IgG1) (Becton Dickinson); antiCD56:Leu19 (IgG1) (Becton Dickinson); anti-CD45RO:UCHL1 (IgG2a) (kindly provided by P. Beverley, ICRF, London, UK); antiCD45RA:2H4 (IgG1) (Coulter Clone, Margency, France); antiCD29:4B4 (IgG1) (Coulter Clone); anti-HLA class II-DR:(IgG2a) (Becton Dickinson); anti-CD25:RIL2 (IgG1) (Becton Dickinson); antimembrane IgM (Nordic Immunology, Tilburg, The Netherlands); anti-4F2 (11) (kindly provided by M. L. Gougeon, Pasteur Institute, Paris, France); anti-CD71 (IgG1) (Immunotech).

Immunocytochemistry on isolated cells. Direct fluorescence staining was performed using phycoerythrin (PE)- or FITC-conjugated monoclonal antibodies. An FITC-conjugated goat anti-mouse Ig (Nordic) was used for indirect immunofluorescence. The analysis was performed using a FACS ${ }^{\star}$ STAR PLUS (Becton Dickinson).

Immunohistochemistry. Biopsy specimens were snap-frozen in isopentane, cooled in liquid nitrogen, and stored at $-70^{\circ} \mathrm{C}$. A three-step indirect immunoperoxidase technique (12) was applied to serial cryostat sections to reveal surface staining of lymphocytes by the various MAbs.

Cell cultures. Proliferative assays were performed as described elsewhere (13). Briefly, PBMC were stimulated either for $3 \mathrm{~d}$ by mitogens or for $6 \mathrm{~d}$ by antigens and allogeneic cells. Anti-CD3, anti-CD2, PHA (Difco Laboratories, Inc., Detroit, MI; final dilution 1/700), and the association of phorbol myristate acetate (PMA) (Sigma Chemical Co., St. Louis, MO) and ionomycine (Calbiochem-Behring Corp., San Diego, CA) were used as mitogens. Antigen-specific T cell proliferation was induced by tetanus toxoid (Pasteur Institute, Marne La Coquette, France) or candidin (Pasteur Institute; final dilution 1/250).

DNA analysis. Total genomic DNA was extracted from E-rosette positive peripheral blood cells and polymorphonuclear cells (14). $10 \mu \mathrm{g}$ was digested to completion with selected restriction endonucleases (EcoRI, HindIII, Xbal, KpnI). The restriction fragments were sizefractionated by electrophoresis on $0.9 \%$ agarose gels and blotted onto nylon filters (Hybond $\mathrm{N}^{+}$; Amersham, les Ulis, France) in $0.4 \mathrm{M}$ $\mathrm{NaOH}$. The filters were screened using a 770-bp cDNA T $\beta$ constant region (15), the $\mathrm{J} \gamma 1$ probe (pH60) (16) and the $\mathrm{J} \delta 1$ probe (17). The probes were radioactively labeled using a random primed kit (Boehringer Mannheim GmbH, Mannheim, Germany) and the filters were hybridized in $50 \%$ formamide at $42^{\circ} \mathrm{C}$. The $c \beta$ probe recognizes $\beta 1$ and $\beta 2$ constant regions of the TCR and their rearrangement can be observed with EcoRI and HindIII digests, respectively. The same DNA digests showed rearrangement of $\mathrm{J}_{\gamma 1} 1$ and $\mathrm{J}_{\gamma} 2$ (18), while the KpnI digest was used to study the additional $\mathrm{J} \gamma \mathrm{P}, \mathrm{J} \gamma \mathrm{P} 1$, and $\mathrm{J} \gamma \mathrm{P} 2$ segments (19). Finally, Xbal digests were used to detect $\delta$ chain rearrangements and to identify the rearranged $\mathrm{V}$ genes by the size of the rearranged restriction fragments (17).

Possible maternal cell engraftment was tested by two methods: phenotype of the patients circulating $T$ cells was determined with the hypervariable marker M27 $\beta$ by reprobing the HindIII DNA digest used for TCR analysis in comparison to HindIII DNA digest prepared from the whole blood cells of their respective mothers. The M27 $\beta$ probe revealed a variable number of tandem repeats (VNTR) at the DXS255 locus with a heterozygote $>90 \%(20)$.

Search for infiltration by maternal lymphocytes of gut and skin of patient 3 was performed on DNA isolated from frozen serial cryostat sections as follows: $104-\mu \mathrm{m}$ section cuts were placed in a $1.5-\mathrm{ml} \mathrm{Ep}$ pendorf tube in the presence of $200 \mu \mathrm{l}$ of solution containing $8 \mathrm{M}$ urea, $2 \%$ SDS, $0.01 \mathrm{M}$ EDTA, $0.3 \mathrm{M} \mathrm{NaCl}$, and $0.01 \mathrm{M}$ Tris (pH:8). Proteinase $\mathrm{K}(100 \mu \mathrm{g} / \mathrm{ml})$ was added and incubation performed during $16 \mathrm{~h}$ at $37^{\circ} \mathrm{C}$. Following phenol and chloroform extraction, the DNA was precipitated and the pellet redissolved in $10 \mu \mathrm{l}$ of Tris EDTA (10:1). Polymerase chain reaction (PCR) was performed on $1 \mu l$ of the DNA preparation using the primers MX57 and MZ68 at the D9S15 locus as previously described (21). One tenth of each reaction mixture was analyzed on an $8 \%$ polyacrylamide/8 $\mathrm{M}$ urea sequencing gel.

\section{Results}

The number of patients' blood T cells was always high (Table I) and phenotype studies of these cells revealed several remarkable features. A given T cell subset predominated in every case: the $\mathrm{CD} 8^{+} \mathrm{TCR} \alpha \beta^{+}$subset accounted for the majority of blood $\mathrm{T}$ cells in four patients and the $\mathrm{CD} 4^{+} \mathrm{TCR} \alpha \beta^{+}$subset in one. In patient 3 , there was a marked increase in $\gamma \delta^{+} \mathrm{T}$ cells. Two-color flow cytometry (Fig. 2) revealed that most $\gamma \delta^{+} \mathrm{T}$ cells from this patient expressed CD8 while a minority expressed neither CD8 nor CD4. Using anti-V $\delta$ and $V \boldsymbol{\gamma}$-specific MAbs, it was found that all $\gamma \delta^{+} \mathrm{T}$ cells were labeled by an anti-V $\delta 1-\mathrm{J} \delta 1$ antibody ( $\delta \mathrm{TCS} 1$ ), while anti- $\mathrm{V} \gamma 9$ and anti-V $\delta 2$ did not bind to $\gamma \delta^{+} \mathrm{T}$ cells (data not shown). In contrast, the percentage of $\gamma \delta^{+} \mathrm{T}$ cells in the other three patients studied was very low (Table I).

As shown in Table II, a high proportion of the patients' $T$ cells expressed activation antigens, especially HLA class II molecules and 4F2 (except in patient 1). An increased level of CD71 was also detected in three cases and CD25 T cells were present in one patient. Conversely, a high proportion of the patients' $T$ cells expressed markers of memory $T$ cells (CD45RO and CD29). This was particularly remarkable in these very young children.

As shown in Table III, anti-CD2 antibodies-induced proliferation was negative in all patients while PMA-ionomycine association induced a normal lymphocyte proliferation. Anti-

Table I. Immunofluorescence Phenotypic Analysis of the Peripheral Blood Lymphocyte Population of Five Patients with Omenn's Syndrome

\begin{tabular}{lrrrrrr}
\hline & \multicolumn{5}{c}{ Percentage of positive cells } \\
\cline { 2 - 6 } \multicolumn{1}{c}{ Antigens tested } & \multicolumn{5}{c}{ Patients } & Age-matched \\
\cline { 2 - 6 } normal values \\
\hline CD2 & \multicolumn{7}{c}{2} & 3 & 4 & 5 & ND & $60-80$ \\
CD3 & 97 & 93 & 96 & 94 & 74 & $50-80$ \\
CD4 & 81 & 81 & 87 & 89 & 74 & $35-50$ \\
CD8 & 29 & 37 & 27 & 85 & 30 & $15-20$ \\
TCR alpha beta & 54 & 45 & 37 & 5 & 30 & $50-80$ \\
TCR delta & 81 & 84 & 51 & 90 & ND & $1-5$ \\
CD3+ (CD4- CD8 $\left.{ }^{-}\right)$ & 0 & 2 & 35 & 2 & ND & $0-2$ \\
Surface Ig & 0 & 2 & 24 & ND & ND & 0 \\
CD56 & 0 & 1 & 0 & 2 & 0 & $2-15$ \\
& 11 & 15 & 6 & ND & ND & $1-10$ \\
\hline
\end{tabular}

ND, not done. 


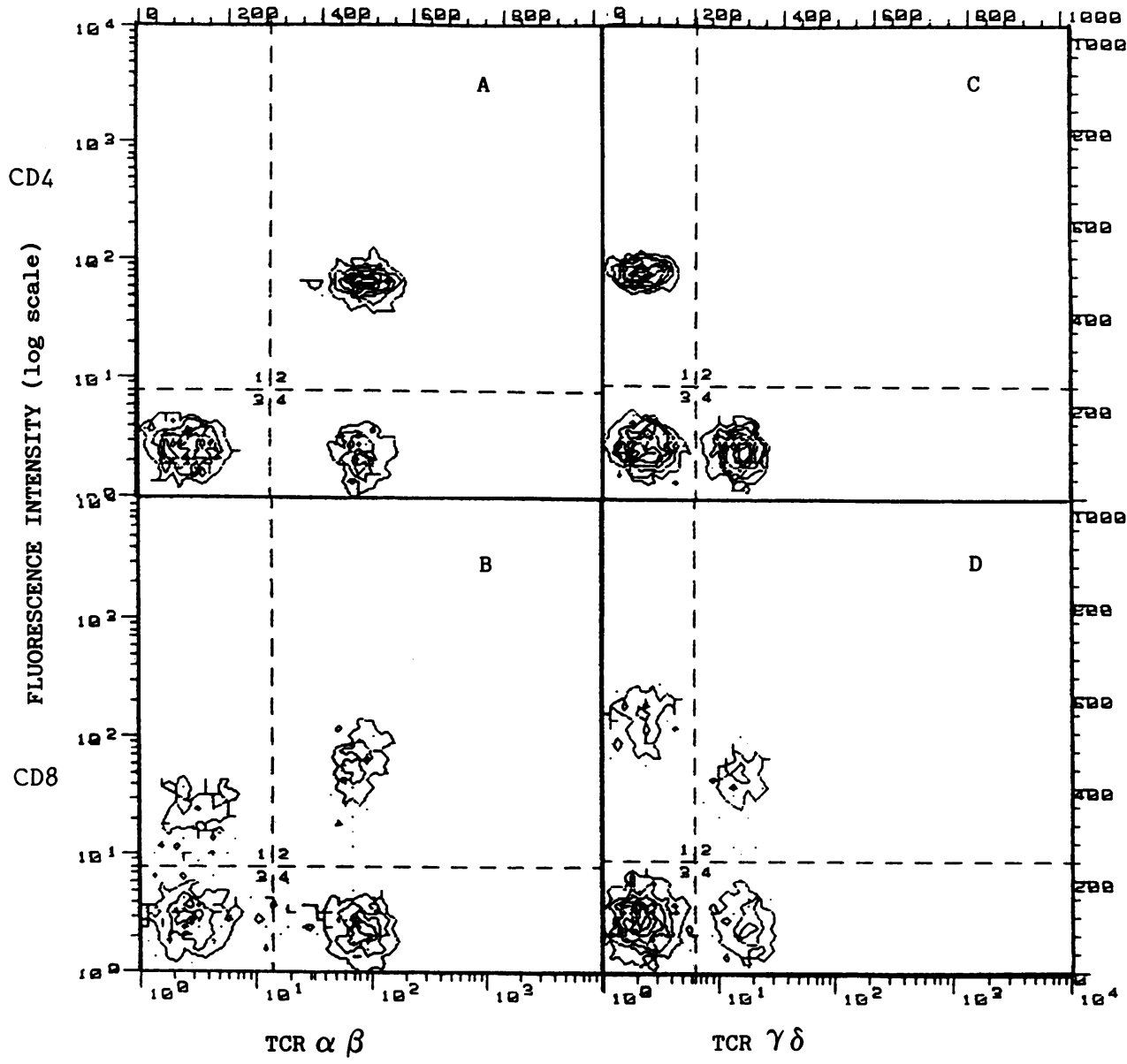

FLUORESCENCE INTENSITY ( $\log$ scale)
Figure 2. TCR, CD4, and CD8 expression (double immunofluorescence) on $T$ lymphocytes of patient 3. TCR $\alpha \beta, \operatorname{TCR} \gamma \delta, \mathrm{CD} 4$, and CD8 were tested, respectively, with FITC-conjugated BMA031, FITCconjugated TCR $\delta 1$, PE-conjugated Leu3a, and PE-conjugated Leu2a. Fluorescence intensity is expressed in $\log$ scale. The fluorescence of TCR $\alpha \beta$ ( $x$ axis in panels $A$ and $B)$ and TCR $\gamma \delta$ ( $x$ axis in panels $\mathrm{C}$ and $\mathrm{D})$ on $\mathrm{CD} 4^{+}$cells $(y$ axis, panels $A$ and $C$ ) and $\mathrm{CD}^{+}$ cells ( $y$ axis, panels $B$ and $D$ ) were studied using double fluorescence.
CD3 and PHA-induced proliferations varied from patient to patient. In contrast, antigen-induced responses were always absent.

Few or no surface Ig-positive cells were found in the blood of the five patients (Table I). Natural killer (NK) cell counts

Table II. Immunofluorescence Analysis of the Activation Antigens Expressed by $\mathrm{CD}^{+}$Lymphocytes of Four Patients with Omenn's Syndrome

\begin{tabular}{lccccc}
\hline & \multicolumn{4}{c}{ Percentage of positive cells } \\
\cline { 2 - 5 } & \multicolumn{4}{c}{ Patients } & $\begin{array}{c}\text { Age-matched } \\
\text { normal values }\end{array}$ \\
\cline { 2 - 5 } Antigens tested & 1 & 2 & 3 & 4 & $0-5$ \\
\hline 4F2 & 0 & ND & 79 & 97 & $0-5$ \\
CD71 & 0 & 15 & 16 & 10 & $0-2$ \\
CD25 & 5 & 37 & 5 & 0 & $0-2$ \\
HLA-DR & 30 & 51 & 85 & 57 & $10-40$ \\
CD29 & ND & 98 & 57 & 85 & $10-40$ \\
CD45RO & ND & 80 & 50 & 73 & $50-90$ \\
CD45RA & ND & 24 & 55 & 8 & \\
& & & & &
\end{tabular}

ND, not done.
(CD56) and NK cytotoxicity (data not shown) were within the normal range.

Skin biopsies performed in three patients $(2,3$, and 4$)$ showed lymphocytic infiltration that involved dermis and, to a lesser extent, epidermis. Keratinocyte lesions were seen near areas of $\mathrm{T}$ cell infiltration. The keratinocytes were strongly HLA-DR(+). However, in contrast to typical GVHD skin alterations, $\mathrm{CDI}(+)$ Langerhans cells were present in the epidermis. Lymphocytes were CD3(+), HLA DR ${ }^{+}$, and for a small number of them, $\mathrm{CD} 25^{+}$. In patients 2 and $4, \mathrm{CD}^{+}$cells were mainly $\beta \mathrm{Fl}^{+}$and only occasional TCR $\delta 1^{+}$cells were seen within the epidermis. In patient 3 , the epidermis was infiltrated by both $\beta \mathrm{F} 1^{+}$and TCR $\delta 1^{+} \delta \mathrm{TCS1} 1^{+}$cells, while only TCR $\alpha \beta^{+} \mathrm{T}$ cells were present in the dermis (Fig. 3, $C$ and $D$ ). In the gut, the $T$ cells detected in the lamina propria belonged to the TCR $\alpha \beta(+)$ subset, while most intraepithelial T lymphocytes were $\gamma \delta(+) \mathrm{V} \delta 1 \mathrm{~J} \delta 1(+)$ (Fig. 3, $A$ and $B$ ).

Patients' $T$ cell populations, either circulating or infiltrating the skin and the gut, were shown not to contain maternal cells, ruling out the etiology of maternal engraftment in the manifestation of Omenn's syndrome. Neither HLA typing and/or caryotyping (data not shown), nor DNA haplotype analysis using a VNTR probe of the $X$ chromosome revealed the presence of the maternal haplotype. Results obtained on circulating $T$ cells 
Table III. Functional Analysis of the Lymphocyte Population of Two Patients with Omenn's Syndrome

\begin{tabular}{|c|c|c|c|c|c|}
\hline & \multicolumn{4}{|c|}{ Patients } & \multirow{2}{*}{$\begin{array}{l}\text { Age-matched } \\
\text { normal values }\end{array}$} \\
\hline & 1 & 2 & 3 & 4 & \\
\hline T lymphocytes / $\mu$ l & $6,300 \pm 1,200$ & $7,400 \pm 1,100$ & $7,400 \pm 1,300$ & $6,500 \pm 800$ & $1,800 \pm 500$ \\
\hline \multicolumn{6}{|c|}{ Mitogen-induced proliferation* $\left(\mathrm{cpm} \times 10^{-3}\right)$} \\
\hline Medium & $1.5 \pm 0.4$ & $2.0 \pm 0.2$ & $2.0 \pm 0.1$ & $2.0 \pm 0.3$ & $0.8 \pm 0.3$ \\
\hline Phytohemagglutinin & $46 \pm 13$ & $24 \pm 10.0$ & $4.0 \pm 0.0$ & $83.0 \pm 24.0$ & $126.0 \pm 37.0$ \\
\hline OKT3 $(50 \mathrm{ng} / \mathrm{ml})$ & $20 \pm 6.3$ & $15 \pm 1.7$ & $10.0 \pm 3.0$ & $9.0 \pm 3.0$ & $36.0 \pm 23.0$ \\
\hline Anti-CD2 antibodies & $11 \pm 4.5$ & $1 \pm 0.2$ & $1.0 \pm 0.1$ & $1.5 \pm 0.5$ & $110.0 \pm 55.0$ \\
\hline PMA-ionomycine & ND & $45 \pm 11.5$ & ND & $102.0 \pm 8.0$ & $168.0 \pm 62.0$ \\
\hline \multicolumn{6}{|c|}{ Antigen-induced proliferation ${ }^{\ddagger}\left(\mathrm{cpm} \times 10^{-3}\right)$} \\
\hline Medium & $1.5 \pm 0.6$ & ND & $0.8 \pm 0.2$ & $2.0 \pm 0.3$ & $1.2 \pm 0.6$ \\
\hline Tetanus toxoid & ND & ND & $1.0 \pm 0.1$ & $1.0 \pm 0.1$ & $34.0 \pm 21.6$ \\
\hline Candida antigens & $2.0 \pm 0.3$ & ND & $1.0 \pm 0.1$ & $1.0 \pm 0.0$ & $35.0 \pm 17.4$ \\
\hline Streptococcal antigens & ND & ND & ND & $1.0 \pm 0.1$ & $11.0 \pm 3.0$ \\
\hline Influenza virus & ND & ND & ND & $1.0 \pm 0.1$ & $15.0 \pm 25.0$ \\
\hline Allogeneic cells & $5.0 \pm 0.7$ & ND & $1.8 \pm 0.2$ & $2.0 \pm 0.3$ & $35.0 \pm 17.4$ \\
\hline
\end{tabular}

* Mitogen proliferation was performed during $3 \mathrm{~d}$. Results are mean of triplicate values $\pm 1 \mathrm{SD}$. ${ }^{\ddagger}$ Antigen proliferation was performed during $6 \mathrm{~d}$. ND, not done.

of patients 3 and 4 compared with their mothers' are reported in Fig. $4 \mathrm{~A}$. Only one of the two maternal alleles were detected in the $T$ cell population of the respective child. Patient 4 , who is a boy, presented a unique allele. Similar results were obtained for patients 1 and 2 (data not shown). Maternal origin of cells infiltrating the tissues of patient 3 was similarly eliminated, since amplification of a polymorphic tandem repeat on the DNA isolated from the skin and the gut of this patient, compared with the one performed on the DNA of her mother and father, revealed the presence of only the patient's haplotype (Fig. $4 B$ ).

Because of the peculiar $T$ cell phenotypes found in the blood and tissues, we studied the rearrangement of the $T$ cell receptor genes in order to detect possible limitation in TCR rearrangements. $T$ cells from the four patients studied showed discrete nongermline band rearrangements with the $C \beta$ probe and/or $\mathrm{J} \gamma 1$ and $\mathrm{J} \delta 1$ probes (Table IV). TCR gene rearrangement could not be studied in patient 5 as the relevant techniques were unavailable. As shown in Fig. $5 A$ (patient 4) the $C \beta 1$ and $C \beta 2$ germline bands have nearly disappeared, indicating that the $C \beta 1$ chain TCR gene is deleted in the majority of the peripheral $T$ cells, whereas the $C \beta 2$ locus is rearranged. Four nongermline bands of two different intensities were revealed by the $\mathrm{C} \beta$ (Fig. $5 A$, arrows) and $\mathrm{J} \gamma 1$ probes (Fig. $5 B$, arrows), while $\mathrm{J} \delta$ genes appeared to be totally deleted (Fig. 6). These results indicate that in this patient, the major part of the $T$ cell population is restrained within two to four clones with rearranged $\alpha$ (deletion of $\mathrm{J} \delta$ ), C $\beta 2$, and $\gamma$ TCR genes. In patient 3 , analysis of the TCR gene rearrangements revealed two nongermline bands, one corresponding to a $\mathrm{C} \beta 2$ gene rearrangement (Fig. $5 A$ ) and the other being a $\mathrm{V} \delta 1$ to $\mathrm{J} \delta 1$ rearrangement (Fig. 6). The $\mathrm{J} \gamma$ rearrangements were analyzed with EcoRI, HindIII, and KpnI digests. The KpnI digest only revealed the presence of a single $\mathrm{Jp} 1 \gamma$ gene rearrangement, with the absence of all other $\mathrm{J}_{\boldsymbol{\gamma}}$ rearrangements normally found in polyclonal $\mathrm{T}$ cell populations (18) (Fig. $5 \mathrm{~B}$ ). Discrete nongermline bands were also found in the other two patients. Patient 1 showed a clonal rearrangement of the $\beta 1, \beta 2$, and $\gamma$-chain genes, associated with a deletion of the $\delta$ gene. Patient 2 presented a nongermline band of very low intensity on $\mathrm{C} \beta 1$ and $\mathrm{V} \delta 2-\mathrm{J} \delta 1$ chain genes and a restriction of the $\gamma$ gene rearrangement on $\mathrm{V} \gamma \mathrm{I}$ or III, J1, or J2 gene with the KpnI digest (data not shown).

\section{Discussion}

Omenn's syndrome is a genetic disorder with recessive autosomal inheritance (1-9), characterized by lymphocytic infiltration of the skin, gut, liver, and spleen, leading to erythroderma and protracted diarrhea with failure to thrive. Blood T lymphocyte and eosinophil numbers are high, but there is marked lymphocyte depletion in the thymus and lymphoid tissues (19). The syndrome is clearly due to an intrinsic defect of the lymphocyte lineage since it is curable by bone marrow transplantation (22). We have further characterized the immunological abnormalities in Omenn's syndrome by studying five patients with typical features. Elevated numbers of $T$ cells were found in the blood, skin, and gut, some of which had phenotype of activated $T$ cells. The $T$ cells could be activated to some extent by mitogens but not by antigens. A given subset of $\mathrm{T}$ lymphocytes (TCR $\alpha \beta^{+} \mathrm{CD} 4^{+}, \alpha \beta^{+} \mathrm{CD} 8^{+}$, or $\gamma \delta^{+}$) represented the majority of the blood $\mathrm{T}$ cells in each patient. It is interesting that all the $\gamma \delta(+) \mathrm{T}$ cells whether $\mathrm{CD}^{+}$or $\mathrm{CD}^{-}$in patient 3 expressed the same $\mathbf{V} \delta 1 \mathrm{~J} \delta 1$ products by immunofluorescence, a phenotype that is normally expressed only by a minority of $\gamma \delta$ $T$ cells (10). Tissue lesions in this patient were infiltrated either by TCR $\alpha \beta(+)$ or TCR $\gamma \delta(+)$ T cells, depending on the location in the tissue (epidermis versus dermis, lamina propria versus epithelium). Circulating $\mathrm{T}$ cell population of these patients as well as those infiltrating skin and gut of patient 3 were shown 

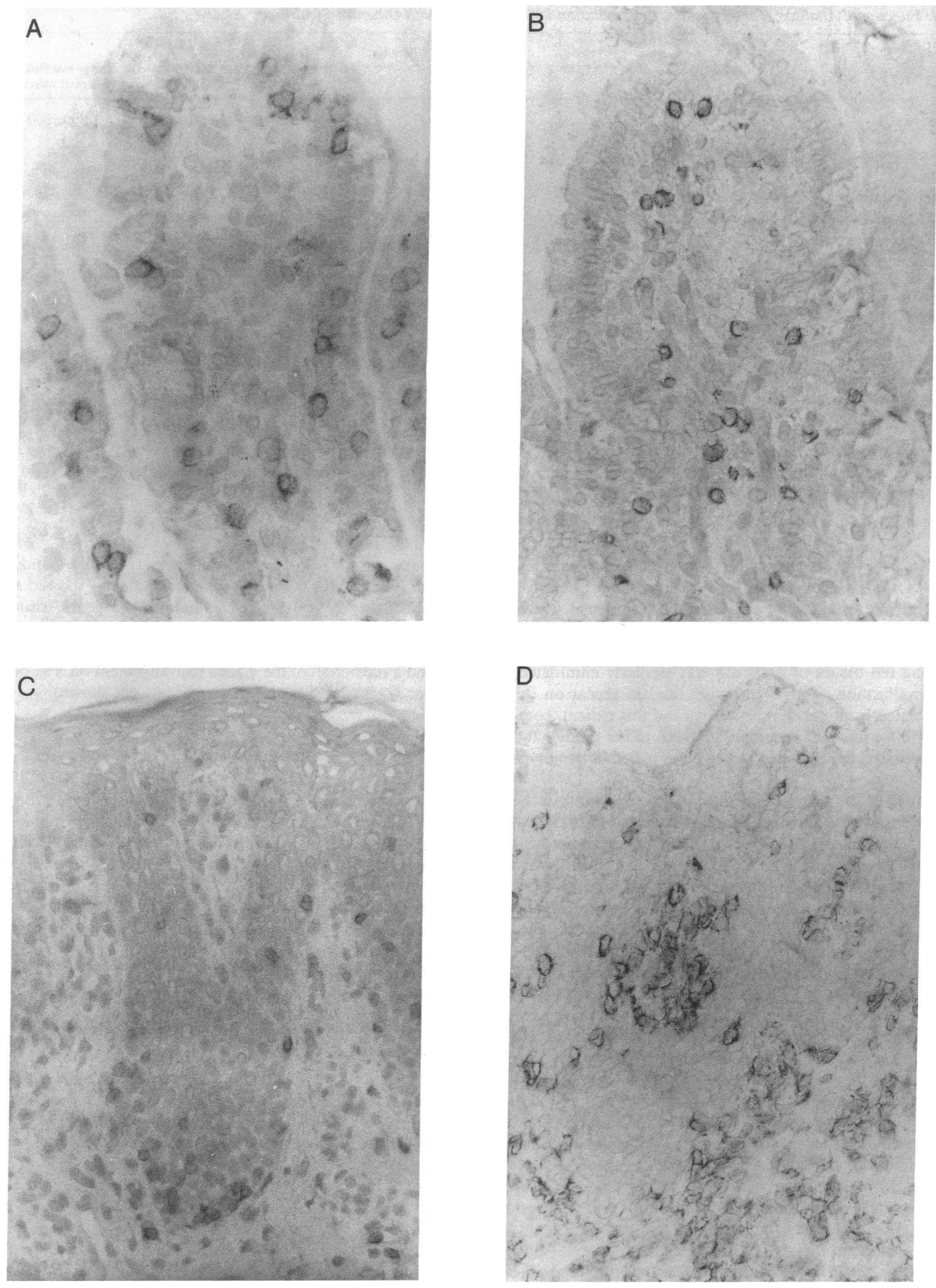
$\mathbf{A}$

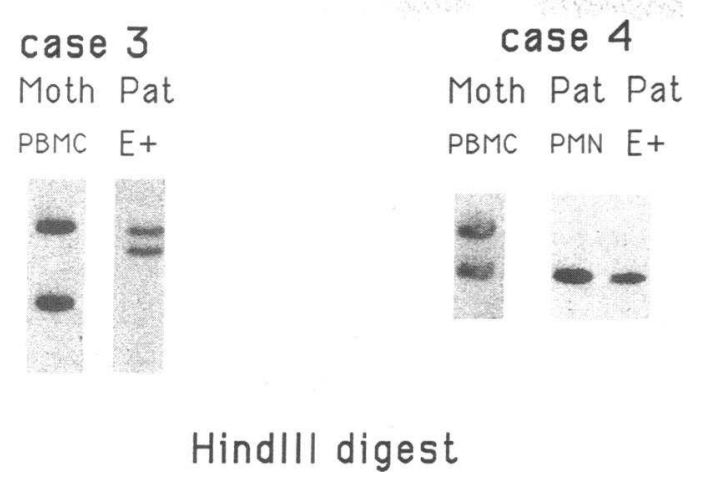

B

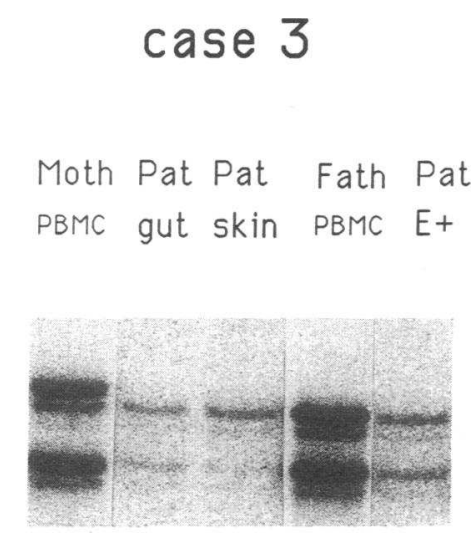

Figure 4. Haplotype analysis of DNA isolated from different tissues of patients with Omenn's syndrome. $(A)$ Polymorphic patterns were detected on Southern blot prepared with DNA isolated from the circulating $T$ cells of patients with Omenn's syndrome and their mothers using the M27 $\beta$ probe at the DXS255 locus. (B) Polymorphic pattern detected at the D9S15 locus on DNA isolated from blood T cells, skin, and gut of patient 3 compared to paternal and maternal haplotypes. The polymorphism was analyzed by polymerase chain reaction using a single end-labeled primer.

not to contain maternal cells since neither HLA typing, caryotyping, nor DNA haplotype analysis revealed the presence of maternal elements. TCR gene rearrangement analysis revealed the presence of several clones in the four patients analyzed. The proportion of each clone in the $\mathrm{T}$ cell population was difficult to assess except in patient 4 where two to four TCR $\beta$ rearranged clones represented the majority of his peripheral T cell population. In patient 3 , the high proportion of $\mathrm{V} \delta 1 \mathrm{~J} \delta 1$ rearrangement observed, was in accordance with the large subset of CD3 $\gamma \delta$ T cells that was also revealed by the anti-V $\delta 1 \mathrm{~J} \delta 1$ monoclonal antibody. This patient also displayed a $\beta 2$ clonal rearrangement. As Southern analysis only reveals clonal rearrangements corresponding to at least $5 \%$ of the total DNA, other undetectable clones may be present in the $\mathrm{T}$ cell popula-
Table IV. TCR Gene Rearrangement Analysis of the T Lymphocyte Population of Four Patients with Omenn's Syndrome

\begin{tabular}{lllll}
\hline & \multicolumn{4}{c}{ TCR Number of nongermline bands } \\
\cline { 2 - 5 } & 1 & 2 & 3 & 4 \\
\cline { 2 - 5 } & 1 & 1 & 0 & 0 \\
\hline C $\beta 1$ & 1 & 0 & 1 & 4 \\
C $\beta 2$ & 1 & 1 & 1 & 4 \\
J $\gamma$ & 0 & 1 & 1 & 0 \\
J $\delta$ & & & & \multicolumn{4}{c}{ Patients }
\end{tabular}

tion of these children. This phenotypic and molecular analysis strongly suggests that the $T$ lymphocyte population in patients with Omenn's syndrome corresponds to the clonal expansion of $\mathrm{T}$ cells with a limited repertoire. Very similar findings have been reported in another patient with this syndrome (9). Most of the patient's $T$ cells belonged to a given $T$ cell subset, i.e., $\mathrm{CD} 4(-) \mathrm{CD} 8(-) \mathrm{TCR} \alpha \beta(+)$, and discrete bands of rearranged $C \beta 1$ were detected (9). It is noteworthy that $(a)$ the $\mathrm{T}$ cell subsets in each patient used different rearranged $C \beta$ and/or $V \boldsymbol{\gamma} \boldsymbol{J}$, $\mathrm{V} \delta \mathrm{J} \delta$ gene elements and $(b)$ the degree of oligoclonality varied from patient to patient. This shows that the syndrome does not cause preferential use of a limited number of clones of a given $T$ cell subset and suggests anomalies of variable extents in the $T$ cell repertoire.

Oligoclonal expression of $\mathrm{T}$ cells that show random rearrangement and expression of TCR chain genes have been described in two murine immunodeficiencies, nude mice (23) and SCID mice (24). In both situations, $T$ cells that develop with age display an oligoclonal repertoire. In SCID mice, the defect in the immunoglobulin and TCR gene rearrangement process $(25)$ is responsible for the lymphocyte deprivation. However, with age, most SCID mice develop mature "leaky" lymphocytes with a restricted heterogeneity of normally rearranged $T$ and $B$ antigen receptors (26). In nude mice, early occurrence of $\gamma \delta(+)$ T cells with restricted heterogeneity has been described, followed later by $\alpha \beta(+)$ oligoclonal T cells (27).

The occurrence in the same family of alymphocytosis-type SCID and Omenn's syndrome strongly suggests that the two conditions correspond to different expressions of the same defect, although the oligoclonality of the $T$ cells was not proven in the patient with Omenn's syndrome. It therefore appears that Omenn's syndrome may correspond to the emergence of a limited number of leaky $T$ cell clones within the context of SCIDtype defective $T$ cell differentiation.

This putative leakiness may have two causes. As in the nude model, limited extrathymic $\mathrm{T}$ cell differentiation may occur, especially in the vicinity of epithelial tissue, e.g., in the skin and gut. This hypothesis is supported by the absence of T cell differentiation in the thymus of the patients (5-8). Another explana-

Figure 3. Immunoperoxidase staining of skin and gut with anti-TCR monoclonal antibodies $(\times 250)$. In the intestinal small biopsy of patient 3 TCR 1 (anti-TCR $\gamma \delta)$ MAb revealed most intraepithelial lymphocytes and only occasional cells in lamina propria $(A)$. Conversely, $\beta$ F1 (anti$\mathrm{TCR} \alpha \beta)$ revealed most lamina propria T cells and only a small number of intraepithelial lymphocytes $(B)$. In skin biopsy, TCR $\delta 1$ stained a small number of scattered intraepidermal $\mathrm{T}$ cells but almost no cells in the dermis $(C)$. In contrast, $\beta \mathrm{F} 1$ labeled both scattered intraepidermal and marked dermal T cells infiltrate $(D)$. The cluster of $\beta \mathrm{F} 1^{+}$cells in the middle is located in a dermal papilla. 


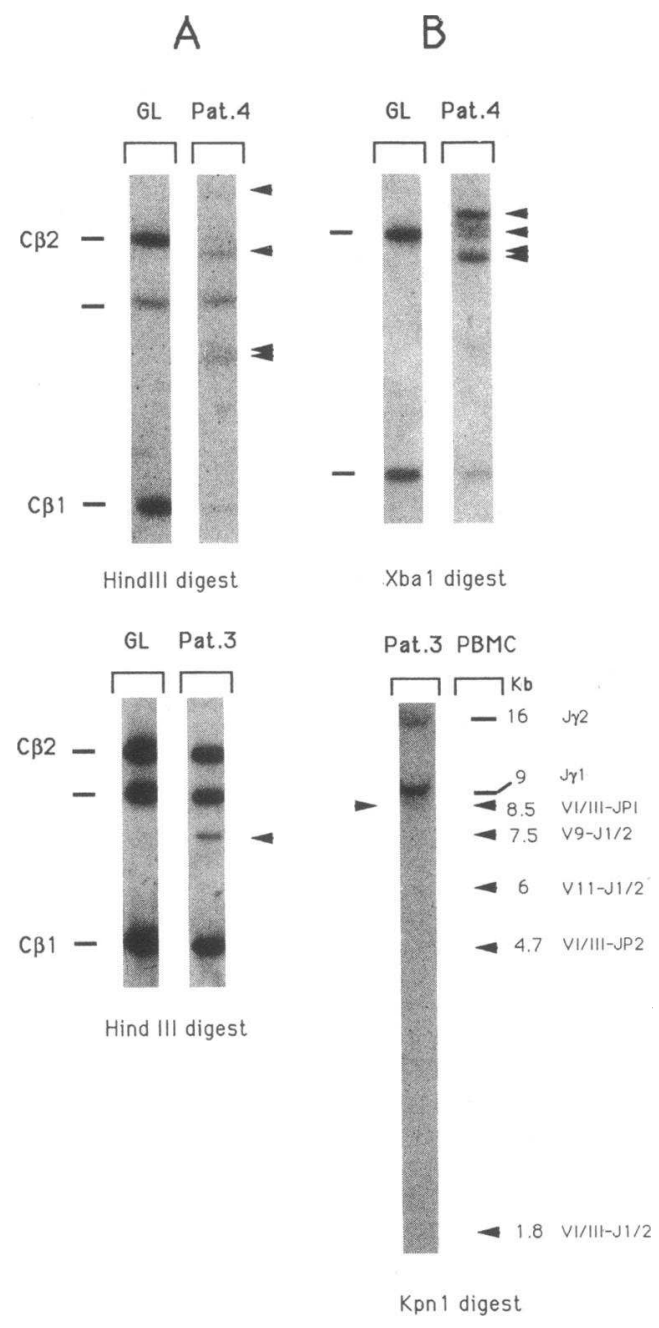

Figure 5. Southern hybridization of $\mathrm{C} \beta(A)$ and $\mathrm{J} \gamma(\mathrm{pH} 60)(B)$ probes to HindIII, Xbal, or KpnI-digested DNA from T cells of patients 3 and 4, nonlymphoid cells $(G L)$, or normal peripheral blood mononuclear cells $(P B M C)$. Germline band, -; nongermline band, $\bullet$. The sizes of the rearrangements and their assignment observed in Kpn 1 digested normal PBMC hybridized with pH60 are indicated (from 19).

tion is based on the possibility that the activated $T$ cells present in the blood and epithelial tissues are directed against self (epithelial) antigens and are therefore expanded. This hypothesis may account for the GVHD-like lesions found in the skin, as well as cytotoxic T cell capacity (9) and localization. Such autoimmune clones of restricted heterogeneity could have escaped negative selection in the thymus (28) because of faulty differentiation. The hypothesis is being tested by the study of skin- and gut-infiltrating $T$ cell reactivity. This situation is reminiscent of the presence of proliferative autoreactive $T$ cells found in autoimmune immunodeficient mice bearing lymphoproliferative and generalized lymphoproliferative disease mutations $(29,30)$. Such animals only express a limited T cell repertoire, due to the use of a limited number of $T$ cell receptor genes (31).

Thus, any cause of defective $\mathrm{T}$ cell differentiation such as abnormal $T$ cell receptor gene rearrangements found in SCID mice (25) might provoke the syndrome. Since the syndrome is

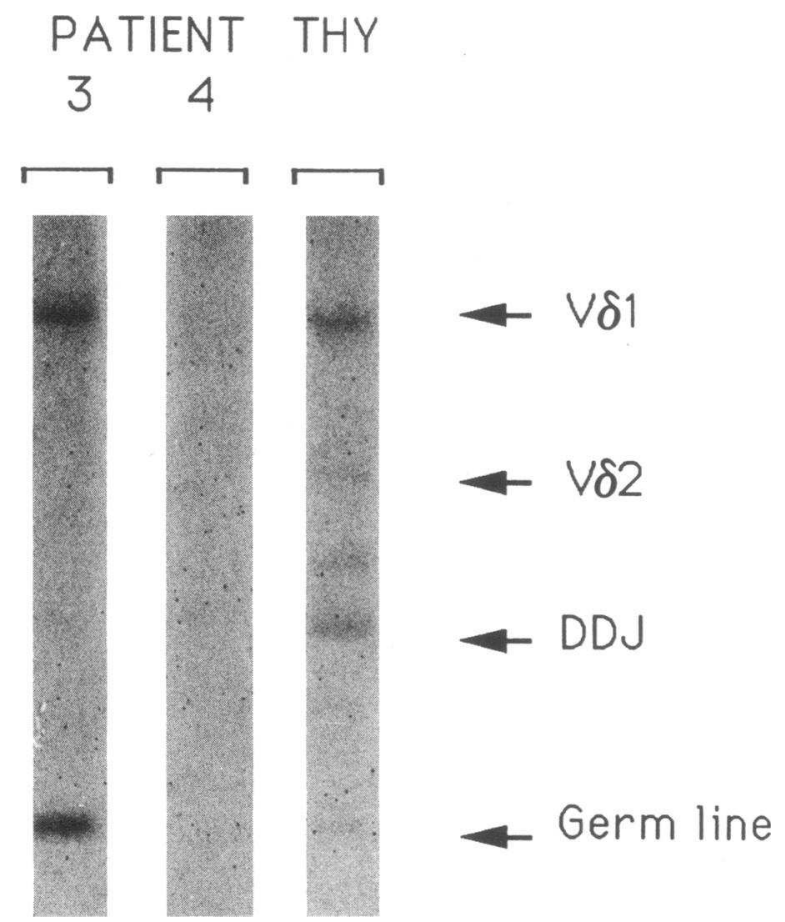

Figure 6. Southern hybridization with the $\mathrm{J} \delta 1$ probe on Xbal-digested DNA from T cells of patients 3 and 4 and normal thymus (Thy). Assignment of the germline band and of the rearrangements observed in the thymus is given on the light (from 17). -, germline band; 4 , nongermline band.

curable by bone marrow transplantation, intrinsic (25) rather than environmental defects (23) have to be considered.

\section{Acknowledgments}

We are grateful for the technical assistance of Ms. C. Harré, C. Jacques, M. C. Pelletreau, and N. de Saint-Sauveur, to the nurse and medical staff who took care of the patients, and to Mrs. D. Bresson for typing the manuscript.

We wish to thank Drs. M. P. Lefranc, T. Rabbitts, and T. W. Mak for the generous gift of $\beta$ and $\gamma$ TCR probes, and A. Hanauer for VNTR analysis. This work was supported by grants from Institut National de la Santé et de la Recherche Médicale, Caisse Nationale d'Assurance Maladie des Travailleurs Salariés to G. de Saint-Basile, and from Association pour la Recherche contre le Cancer to J. P. de Villartay.

\section{References}

1. Omenn, G. S. 1965. Familial reticuloendotheliosis with eosinophilia. $N$. Engl. J. Med. 273:427-432.

2. Barth, R. F., G. E. Vergara, S. K. Khurana, and J. T. Lonman. 1972 Rapidly fatal familial histiocytosis associated with eosinophilia and primary immunological deficiency. Lancet. i:503-506.

3. Cederbaum, S. D., G. Niwayama, E. P. Stiehm, et al. 1974. Combined immunodeficiency presenting as the Letterer Siwe syndrome. J. Pediatr. 85:466471 .

4. Ochs, H. D., S. D. Davis, E. Mickelson, et al. 1974. Combined immunodeficiency and reticuloendotheliosis with eosinophilia. J. Pediatr. 35:463-465.

5. Cohen, A., A. Mansour, H. M. Dosch, and E. W. Gelfand. 1980. Association of a lymphocyte purine ( $5^{\prime}$ nucleotidase) enzyme deficiency with combined immunodeficiency. Clin. Immunol. Immunopathol. 15:245-250.

6. Wyss, M., V. Von Fliedner, E. Jacot des Combes, et al. 1982. A lymphoproliferative syndrome: "cutaneous dystrophy" and combined immune deficiency with lack of helper T-cell factor. Clin. Immunol. Immunopathol. 23:34-49.

7. Ruco, L. P., A. Stoppacciaro, F. Pezzella, M. Mirolo, S. Uccini, P. Barsotti, A. M. Cassano, A. L. Boner, L. Businco, A. Di Fazio, and C. D. Baroni. 1985. The 
Omenn's syndrome: histological, immunohistochemical and ultrastructural evidence for a partial $\mathrm{T}$ cell deficiency evolving in an abnormal proliferation of $\mathrm{T}$ lymphocytes and S-100+/T-6+ Langerhans-like cells. Virchows Arch. (A) 407:69-82.

8. Le Deist, F., A. Fischer, A. Durandy, et al. 1985. Déficit immunitaire mixte et grave avec hyperéosinophilie. Etude immunologique de cinq observations. Arch. Fr. Pediatr. 42:11-16.

9. Wirt, D. P., E. G. Brooks, S. Vaidya, et al. 1989. Novel T-lymphocyte population in combined immunodeficiency with features of graft versus host disease. N. Engl. J. Med. 321:370-374.

10. Miossec, C., F. Faure, L. Ferradini, S. Roman-Roman, S. Jitsukawa, S. Ferrini, A. Moretta, F. Triebel, and T. Hercend. 1990. Further analysis of the T cell receptor $\gamma / \delta^{+}$peripheral lymphocyte subset. The $\mathrm{V} \delta 1$ segment is expressed with either C $\alpha$ or C $\delta$. J. Exp. Med. 171:1171-1188.

11. Mangeney, M., A. Fischer, F. Le Deist, J. P. Latge, and A. Durandy. 1989. Direct activation of human B lymphocytes by Candida albicans-derived mannan antigen. Cell. Immunol. 122:329-333.

12. Jarry, A., N. Cerf-Bensussan, N. Brousse, D. Guy-Grand, F. Muzeau, and F. Potet. 1988. Same peculiar subset of HML-1 + lymphocytes present within normal intestinal epithelium is associated within tumoral epithelium of gastrointestinal carcinomas. Gut. 29:1632-1638.

13. Fischer, A., F. Le Deist, A. Durandy, and C. Griscelli. 1985. Separation of a population of human $\mathrm{T}$ lymphocytes that bind prostaglandin E2 and exert a suppressor activity. J. Immunol. 134:815-819.

14. Old, J. M. 1986. Fetal Analysis in Human Genetic Disease, a Practical Approach. K. E. Devis, editor. CRL Press, Oxford, Washington.

15. Yanagi, Y., A. Chan, B. Chin, M. D. Minden, and T. W. Mak. 1985. Analysis of cDNA clones specific for human T cells and the $\alpha$ and $\beta$ chains of the T cell receptor heterodimer from human T cell line. Proc. Natl. Acad. Sci. USA. 82:3430-3434.

16. Lefranc, M. P., and T. H. Rabbitts. 1985 . Two tandemly organized human genes encoding the T-cell $\gamma$ constant-region sequences show multiple rearrangement in different T-cells types. Nature (Lond.). 316:463-465.

17. De Villartay, J. P., A. B. Pullman, R. Andrade, E. Tschachler, O. Colamenici, L. Neckers, D. I. Cohen, and J. Cossman. 1989. $\gamma / \delta$ lineage relationship within a consecutive series of human precursor T-cell neoplasm. Blood. 74:25082518.

18. Lefranc, M. P., and T. H. Rabbitts. 1989. The human T-cell receptor $\gamma$ (TRG) genes. Reviews Trends in Biochemical Sciences. 14:214-218.
19. Huck, S., and M. P. Lefranc. 1987. Rearrangements to the JP1, JP and JP2 segments in the human T-cell rearranging gamma gene (TRG $\gamma$ ) locus. FEBS (Fed. Eur. Biochem. Soc.) Lett. 224:291-296.

20. Brown, R. M., N. J. Fraser, and G. K. Brown. 1990. Differential methylation of the hypervariable locus DXS255 on active and inactive $\mathrm{X}$ chromosomes correlates with the expression of a human X-linked gene. Genomics. 7:215-221.

21. Fujita, R., A. Hanauer, G. Sirugo, R. Heilig, and J. L. Mandel. 1990 Additional polymorphisms at marker loci D9S5 and D9S15 generate extended haplotypes in linkage disequilibrium with Friedreich ataxia. Proc. Natl. Acad. Sci. USA. 87:1796-1800.

22. Fischer, A., C. Griscelli, W. Friedrich, B. Kubanek, R. Levinsky, G. Morgan, J. Vossen, G. Wagemaker, and P. Landais. 1986. Bone marrow transplantation for immunodeficiencies and osteopetrosis European Survey, 1968-1985. Lancet. ii:1080-1083.

23. Yoshikai, Y., M. D. Reis, and W. T. Mak. 1986. Athymic mice express a high level of functional $\gamma$-chain but greatly reduced levels of $\alpha$ and $\beta$-chain T-cell receptor messages. Nature (Lond.). 324:482-485.

24. Carroll, A. M., R. R. Hardy, and M. J. Bosma. 1989. Occurrence of mature $\mathrm{B}\left(\mathrm{IgM}^{+}, \mathrm{B} 220^{+}\right)$and $\mathrm{T}\left(\mathrm{CD}^{+}\right)$lymphocytes in SCID mice. J. Immunol. 143:1087-1093.

25. Bosma, G. C., R. P. Custer, and M. J. Bosma. 1983. A severe combined immunodeficiency mutation in the mouse. Nature (Lond.). 301:527-529.

26. Bosma, G. C. M. Fried, R. P. Custer, A. Carroll, D. M. Gibson, and M. J. Bosma. 1988. Evidence of functional lymphocytes in some (leaky) SCID mice. J. Exp. Med. 167:1016-1033.

27. McDonald, H. R., R. K. Lees, C. Bron, B. Sordat, and G. Miescher. 1987. $\mathrm{T}$ cell antigen receptor expression in athymic (nu/nu) mice. Evidence for an oligoclonal $\beta$ chain repertoire. J. Exp. Med. 166:195-209.

28. Von Boehmer, H. 1990. Developmental biology of T-cells in T cell-receptor transgenic mice. Annu. Rev. Immunol. 8:531-556.

29. Murphy, E. D. 1981. Lymphoproliferation (lpr) and other single-locus models for murine lupus. In Immunologic Defects in Laboratory Animals. Vol 2. M. E. Gershwin and B. Merchant, eds. Plenum Publishing Corp., New York 143-173

30. Schultz, L. D., and C. L. Sidman. 1987. Genetically determined murine models immunodeficiency. Annu. Rev. Immunol. 5:367-390.

31. Fowlkes, B. J., A. M. Kruisbeek, H. Ton-That, et al. 1987. A novel population of T-cell receptor $\alpha \beta$-bearing thymocytes which predominantly expresses a single V9 gene family. Nature (Lond.). 329:251-254. 